\title{
Microwave Irradiation of Nanohydroxyapatite from Chicken Eggshells and Duck Eggshells
}

\author{
Nor Adzliana Sajahan and Wan Mohd Azhar Wan Ibrahim \\ Department of Biomedical Engineering, Faculty of Engineering, University of Malaya and PPP, 50603 Kuala Lumpur, Malaysia \\ Correspondence should be addressed to Nor Adzliana Sajahan; november.sierral26@gmail.com
}

Received 9 July 2014; Revised 4 September 2014; Accepted 5 September 2014; Published 14 October 2014

Academic Editor: Saeid Zanganeh

Copyright ( 2014 N. A. Sajahan and W. M. A. Wan Ibrahim. This is an open access article distributed under the Creative Commons Attribution License, which permits unrestricted use, distribution, and reproduction in any medium, provided the original work is properly cited.

\begin{abstract}
Due to similarity in composition to the mineral component of bones and human hard tissues, hydroxyapatite with chemical formula $\mathrm{Ca}_{10}\left(\mathrm{PO}_{4}\right)_{6}(\mathrm{OH})_{2}$ has been widely used in medical field. Both chicken and duck eggshells are mainly composed of calcium carbonate. An attempt has been made to fabricate nanohydroxyapatite (nHA) by chicken (CES) and duck eggshells (DES) as calcium carbonate source $\left(\mathrm{CaCO}_{3}\right)$. CES and DES were reacted with diammonium hydrogen $\left[\left(\mathrm{NH}_{4}\right)_{2} \mathrm{HPO}_{4}\right]$ solution and subjected to microwave heating at 15 mins. Under the effect of microwave irradiation, nHA was produced directly in the solution and involved in crystallographic transformation. Sample characterization was done using by X-ray diffraction (XRD), fourier transform infrared spectroscopy (FTIR), and scanning electron microscopy (SEM).
\end{abstract}

\section{Introduction}

Hard tissue is one of the crucial components of our body. Natural bone is a type of nanocomposite containing organic (30\%) and inorganic compounds (70\%) in a form of needleor rod-like materials with length of $25-50 \mathrm{~nm}[1,2]$. There are many alternatives for the replacement of bone due to trauma, accident, or disease. These include autografts, allografts, xenografts, and synthetic biomaterials. However, these methods have some complications. For instance, autografts confront the risk of bone defect of donor-site, limited availability of grafts and it requires additional surgeries for harvesting [3]. Hydroxyapatite (HA) has been reliable as bone substitute due to chemically and biologically resemblance with human native tissue in addition to its crystallographic structure [4, 5]. Generally, $\mathrm{HA}\left(\mathrm{Ca}_{10}\left(\mathrm{PO}_{4}\right)_{6}(\mathrm{OH})_{2}\right)$ constitutes about $69 \%$ of the weight of human bone [6]. It is bioactive, that is, forms a strong bond with bone which enhances the implant fixation and provides stability to the interface between bone and HA ceramic. This characteristic has made HA being used in orthopedics field and in dental implants [7, 8]. This ceramic has been widely known for its properties such as excellent biocompatibility, nontoxicity, noninflammatory, and pyrogenetic response $[8,9]$. HA has also been extensively used as bone filler, implant coating, and cell-culture carrier [10]. Due to poor mechanical reliability of HA ceramic, its applications are limited to nonloading bearing such as bone graft substitution and coatings on metallic implants [11]. It was reported that the debris of HA formed was deposited between the implant interface and the surrounding tissue which encouraged the irritation in cells such as monocytes or macrophages to release inflammatory mediators, cytokines, and matrix metalloproteinases, inducing cytotoxicity and pathologic bone resorption [12]. HA can be produced by various synthesis routes including chemical precipitation method [13], hydrothermal techniques [8], sol-gel route [14], and mechanochemical [15] techniques using different sources of calcium and phosphorus as starting materials. These methods, however, have several disadvantages. Most of HA powders prepared by chemical precipitation route have calcium deficiency and HA powders produced from these methods exhibit thermal decomposition of HA to $\alpha$ - or $\beta$ tricalcium phosphate phase [13]. The obtained HA powders from sol-gel method usually have poor crystallinity and thermal stability [16]. Hydrothermal process is said to be an expensive synthesis method since it involves several steps of 
heat treatment [17]. Zhang and Vecchio [18] have synthesized $\mathrm{HA}$ at temperature of $120^{\circ} \mathrm{C}$ to $180^{\circ} \mathrm{C}$ by using hydrothermal method. The precursors used were dicalcium phosphate anhydrous $\left(\mathrm{CaHPO}_{4}\right)$ and calcium carbonate $\left(\mathrm{CaCO}_{3}\right)$. At temperature of $120^{\circ} \mathrm{C}$, the $\mathrm{CaHPO}_{4}$ was still found after being subjected to heating for $24 \mathrm{hr}$ while $\mathrm{HA}$ was formed along with $\beta$-TCP above temperature of $140^{\circ} \mathrm{C}$. The particles size of HA obtained was $200 \mathrm{~nm}$ in width and several microns in length. Compared with conventional method, microwave synthesis can be used to overcome these disadvantages as it offers fast reaction, easy reproducibility, narrow particle distribution, high yield, high purity, efficient energy transformation, and throughout volume heating [9]. During microwave heating, the sample itself becomes the source of heat. This is due to the fact that the heat is generated internally within the material instead of originating from external heating and subsequent radiative transfer $[9,19]$. It also provides a rapid and shorter synthesis time as its high depths penetration enables the entire substance to be subjected to uniform and rapid heating $[17,20]$. This causes the thermal gradients to minimize and reduce the time for particle diffusion; thus the product can be formed in a shorter time [20]. With the aid of soft template of cetyltrimethylammonium (CTAB), Arami et al. [21] have successfully synthesized nanostrips HA by microwave synthesis technique. The use of CTAB helps in epitaxial growth of nanostructures and controls the size and morphology of the HA. The size of HA obtained was 10 and $55 \mathrm{~nm}$ in width and length, respectively, with a very short time of microwave heating $(2.45 \mathrm{GHz}, 900 \mathrm{~W})$ of 5 minutes. No secondary phases were found. In another work, Meejoo et al. [19] have performed a simple microwaveassisted wet precipitation of HA by immediately subjecting the mixture solution of the starting materials to microwave heating $(850 \mathrm{~W})$ for $20 \mathrm{~min}$. This work did not require a $\mathrm{pH}$ control as reported by others. This is because the calcium hydroxide, $\mathrm{Ca}(\mathrm{OH})_{2}$ precursor, used is a strong base. Even though the HA obtained was calcium deficient HA, it was completely removed after annealing it at $800^{\circ} \mathrm{C}$. A needleshaped particle with nanosize of $50 \mathrm{~nm}$ in diameter and $200 \mathrm{~nm}$ in length has been achieved using this method. In this work, HA powder was synthesized from both chicken and duck eggshells as calcium source using microwave irradiation. This study proposed a straightforward, economic, and reproducible technique for fabrication of HA powder using various waste materials. The effect of microwave power as well as irradiation time on particles morphology will be observed. The characteristics of HA powder produced will be studied for phase composition using X-ray diffraction (XRD), powder morphology using scanning electron microscope (SEM), and functional groups using fourier transform infrared (FTIR).

\section{Materials and Methods}

The commercial $\left(\mathrm{NH}_{4}\right)_{2} \mathrm{HPO}_{4}$ and $25 \%$ liquor ammonia were of analytical grade and used without further purification. $\left(\mathrm{NH}_{4}\right)_{2} \mathrm{HPO}_{4}$ and eggshells were used as phosphate and calcium precursor, respectively. CES were collected and repetitively washed with distilled water and their membranes
TABLE 1: Sample ID and synthesis condition in the synthesis of HA.

\begin{tabular}{lcc}
\hline \multirow{2}{*}{ Sample ID } & \multicolumn{2}{c}{ Synthesis condition } \\
& Microwave power (W) & Irradiation time (min) \\
\hline cHA-900 & 900 & 15 \\
dHA-A900 & 900 & 15 \\
dHA-B900 & 900 & 30 \\
dHA-C900 & 900 & 45 \\
dHA-700 & 700 & 15 \\
\hline
\end{tabular}

were peeled off. They were further boiled in water for $15 \mathrm{~min}$ to remove dirt and organic residue. The cleaned and dried eggshells were then ground to fine powder using agate mortar and pestle. The procedure of this experiment was adapted from Nayar and Guha [22]. The experimental procedure has been modified by increasing the chemical reagent used so that it is suitable for microwave technique and to increase the yield of powder. $25 \mathrm{~g}$ of CES powder was dissolved in $100 \mathrm{~mL} \mathrm{1:3} \mathrm{of} \mathrm{hydrochloric} \mathrm{acid,} \mathrm{HCl}$, and distilled water. The mixture was stirred rigorously for 30 minutes with the help of magnetic stirrer. It was then filtered to eliminate the residue of eggshells. $1850 \mathrm{~mL}\left(\mathrm{NH}_{4}\right)_{2} \mathrm{HPO}_{4}$ solution was added to the eggshells solution and stirred thoroughly. The mixture $\mathrm{pH}$ was maintained 10-11 by adding dropwise of $1: 1$ of $25 \%$ liquor ammonia and distilled water. The mixture was immediately subjected to microwave heating in a domestic oven operating at $2.45 \mathrm{GHz}(900 \mathrm{~W})$ for $15 \mathrm{~min}$. The precipitate formed was centrifuged at the rotation speed of $3000 \mathrm{rpm}$ several times with distilled water to eliminate the remaining ammonia. It was then dried overnight at $100^{\circ} \mathrm{C}$. As-dried precipitate was ground to fine powder. The experiment was repeated exactly using DES. This procedure instruction was repeated for several times obtaining identical phases of the nanoHA powder. The microwave power $(700 \mathrm{~W}$ and $900 \mathrm{~W})$ and irradiation time (15 min, $30 \mathrm{~min}$ and $45 \mathrm{~min}$ ) were varied to study their effect on the HA particles morphology. Table 1 shows the synthesis condition and sample ID. The powder samples were analyzed by XRD (Panalytical) using $\mathrm{Cu}-\mathrm{K} \alpha$ radiation $(1.540600 \AA)$ with voltage and current settings of $45 \mathrm{kV}$ and $40 \mathrm{~mA}$, respectively. The XRD patterns were recorded in step size ( $\left(2 \mathrm{Th}\right.$.) of $0.03^{\circ}$ and step time $1 \mathrm{~s}$. FTIR (Nicolet iS10) was used to determine the functional groups of the sample powders. The FTIR spectra were recorded in the region $400-4000 \mathrm{~cm}^{-1}$ using the $\mathrm{KBr}$ pellet technique. The morphology of sample powders was obtained with a Hitachi model S-3500N scanning electron microscope, operated at $20 \mathrm{kV}$ with magnification of $100 \mathrm{kx}$. Small amount of powder was coated with gold palladium using a sputter coater. Then it was held at the sample holder to observe the images.

\section{Result and Discussion}

One of the important parameters that affects the complete reaction of $\mathrm{HA}$ is alkaline $\mathrm{pH}$ around 9-10 [10]. After the mixing of eggshells solution and $\left(\mathrm{NH}_{4}\right)_{2} \mathrm{HPO}_{4}$, the preliminary $\mathrm{pH}$ of the mixture was around $7-8 \mathrm{pH}$. It was adjusted to $10-11 \mathrm{pH}$ by using $25 \%$ liquor ammonia. It is 


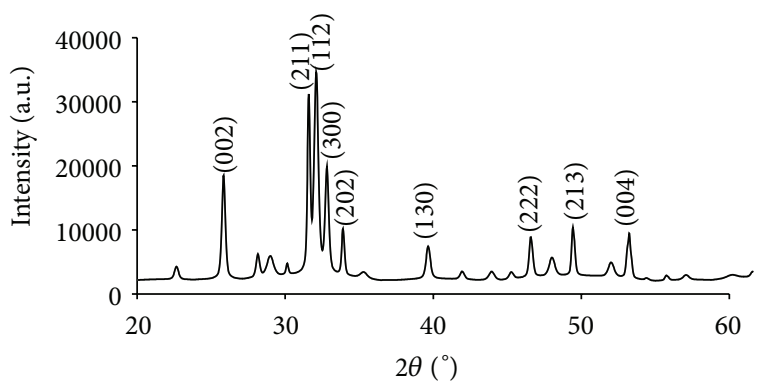

(a)

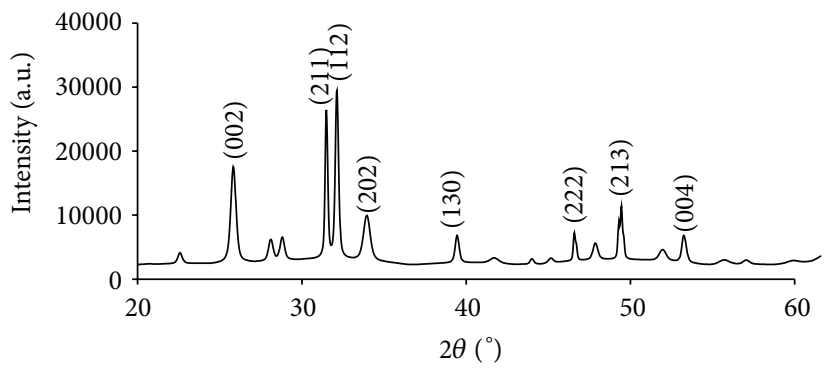

(b)

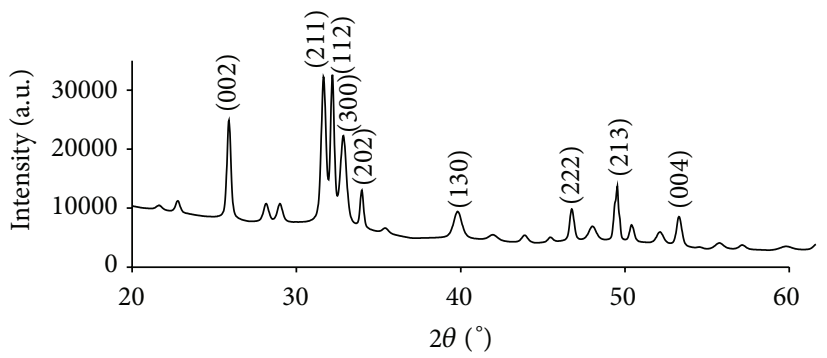

(c)

Figure 1: X-ray diffraction patterns of powder samples (a) dHA-900, (b) cHA-900, and (c) dHA-700.

found that above $\mathrm{pH} \mathrm{10,} \mathrm{pure} \mathrm{crystalline} \mathrm{HA} \mathrm{phases} \mathrm{with}$ narrow size distribution and uniform morphology occurred [10]. However, $\mathrm{pH}$ lower than 10 contributes to the presence of $\beta$-TCP and the morphology of the HA particles tends to be irregular and flaky [10]. The addition of ammonium hydroxide is said to prevent the formation of carbonate during synthesis [23]. Palanivelu et al. [24] found out that, upon synthesized HA at neutral $\mathrm{pH} 7$, secondary phases of calcium deficient HA such as octacalcium phosphate (OCP) and dicalcium phosphate (DCP) also occurred. This was due to the slow rate reaction of ion releasing between the calcium and phosphate precursors in the solution medium. In addition, it also caused the agglomeration of particles. Conversely, the fast rate of mobility of both ions above $\mathrm{pH}$ 9 led to agglomeration. However, it was found that ultrasonic irradiation techniques are suitable for producing $\mathrm{HA}$ at $\mathrm{pH} 9$.

The XRD pattern for product from duck eggshells and chicken eggshells powders is shown in Figure 1. The phase identification was done according to standard JCPDS file 00024-0033. Phase analysis revealed that all major peaks of HA were presented in both powders except for peak at $2 \theta$ angle of $32.87^{\circ}$ for cHA-900 sample and were in a good agreement with standard data for HA which confirmed the formation of HA during microwave heating. However, the disappearance of the peak was not known.

Since microwave radiation provides a rapid heating rate and uniform heating throughout the entire volume of the substance, the energy was sufficient to produce the major peaks of HA at planes of (002), (211), (112), (300), (202), (130), (222), (213), and (004). The XRD patterns of the assynthesized powder show prominent peaks at $2 \theta$ angle of $25.82^{\circ}, 31.57^{\circ}, 32.07^{\circ}, 32.79^{\circ}, 34.00^{\circ}, 39.63^{\circ}, 46.56^{\circ}$, and $49.41^{\circ}$ for dHA-A900 while cHA-900 shows high intensity peaks at $25.81^{\circ}, 31.55^{\circ}, 32.11^{\circ}, 33.93^{\circ}, 39.42^{\circ}, 46.56^{\circ}$, and $49.37^{\circ}$. For dHA-700, the XRD peaks also appeared at $25.87^{\circ}, 31.65^{\circ}$, $32.17^{\circ}, 32.83^{\circ}, 33.96^{\circ}, 39.78^{\circ}, 46.73^{\circ}$, and $49.54^{\circ}$. The absence of other peaks corresponding to impurities such as $\beta$-TCP, $\alpha$-TCP, and calcium carbonate indicates that a pure phase of HA has been synthesized as seen in Figure 1. Upon varying the irradiation time of $15 \mathrm{~min}, 30 \mathrm{~min}$, and $45 \mathrm{~min}$ (results for XRD and FTIR, i.e., $30 \mathrm{~min}$ and $45 \mathrm{~min}$ were not shown and it was done for DES only), it was found that from XRD analysis there was no indication of other secondary phases in all the samples. All peaks corresponding to HA were well presented. The efficient transformation of energy and heating of microwave synthesis caused well-crystallized HA powders to synthesize without calcification or sintering process or further heating as has always been reported by other studies. This can be seen at the sharp and high intensity peaks of both XRD patterns. Prabakaran et al. [25] have successfully synthesized a stoichiometric HA by wet chemical method. They used chicken eggshells as calcium source and the precipitate formed was calcined at various temperatures of $400^{\circ} \mathrm{C}, 700^{\circ} \mathrm{C}$, and $900^{\circ} \mathrm{C}$. It was observed that the calcination process did not alter the phase composition of the HA but the intensity of the XRD pattern became sharper as the temperature rose, that is, crystallinity of the HA tends to be well-crystallized.

Scanning electron microscope observations of the synthesized-HA powders can be seen in Figure 2. High magnification of SEM measurements was taken to locate the particles down to nanometer large surface area. It can be seen that both of cHA-900 and dHA-A900 particles were agglomerated and have irregular round shape. However, the shape of both particles was uniformly distributed. The particles size was calculated using ImageJ software. 


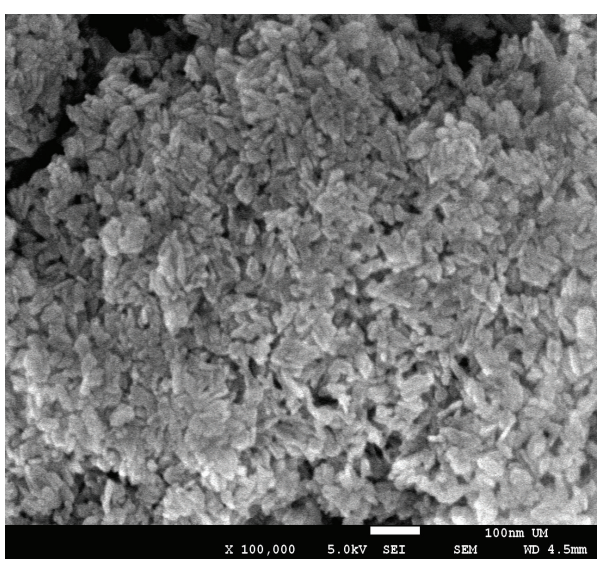

(a)

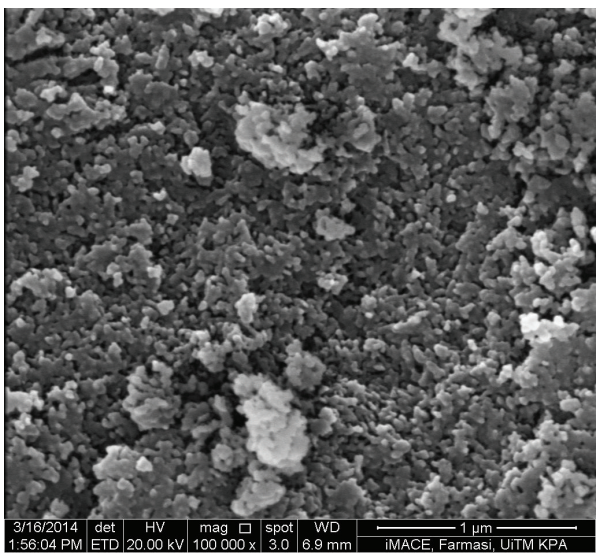

(c)

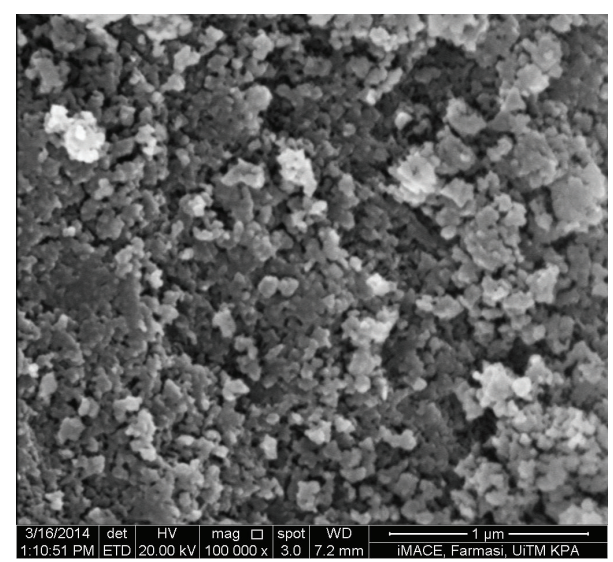

(b)

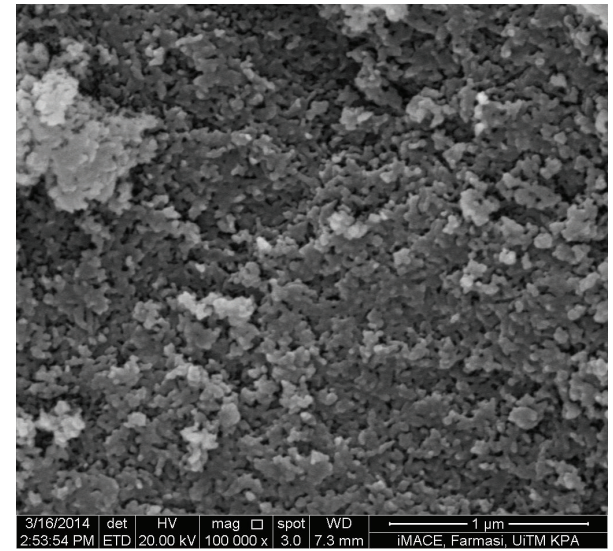

(d)

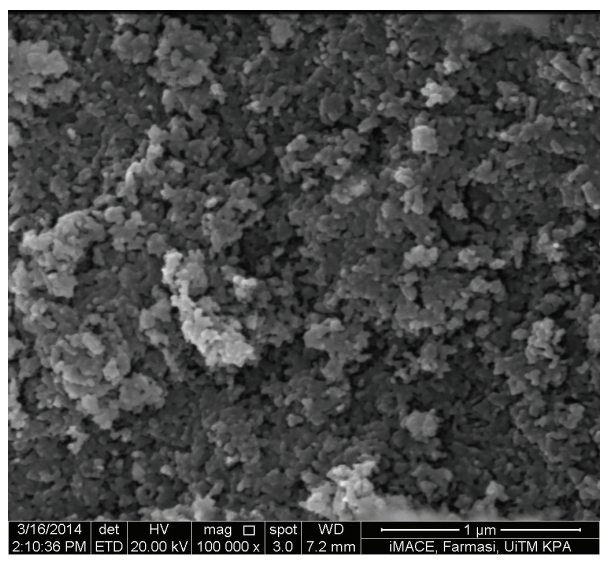

(e)

Figure 2: Scanning electron micrographs of (a) dHA-700, (b) cHA-900, (c) dHA-A900, (d) dHA-B900, and (e) dHA-C900 at magnification of $100 \mathrm{k}$.

The average particle size for both cHA-900 and dHAA900 was found to be $75.82 \mathrm{~nm}$ and $72.48 \mathrm{~nm}$, respectively $(n=100)$. Properties and performance of HA depend on the powder particle size and shape, their distribution, and agglomerates [9]. It is important to achieve nanosized particle as it exhibits many advantages. Nanostructured-HA is said to enhance biocompatibility, bioactivity, and flexibility which provides homogeneous resorption $[9,26]$. Many has reported the works on nano-HA; for example, Liu et al. [27] synthesized a needle-like HA with size of $13-170 \mathrm{~nm}$ in length and $15-25 \mathrm{~nm}$ in width using hydrothermal process. By using wet precipitation technique, Monmaturapoj [28] has successfully synthesized irregular nanosized HA of $\sim 25 \mathrm{~nm}$ by varying the concentration of the precursors. However, there was slight difference of HA particles shape, size, and agglomeration with increase of microwave heating. Upon 


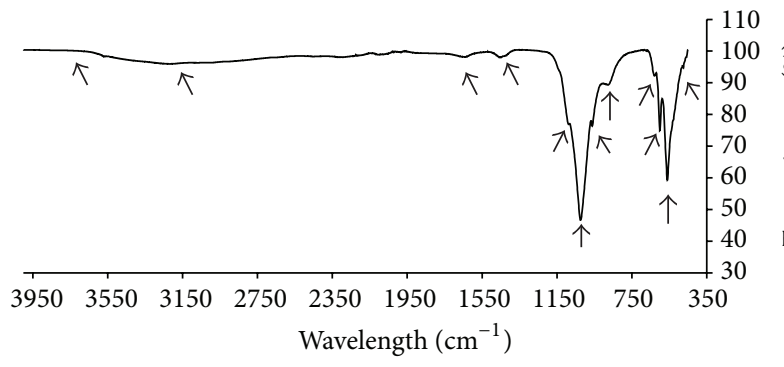

(a)

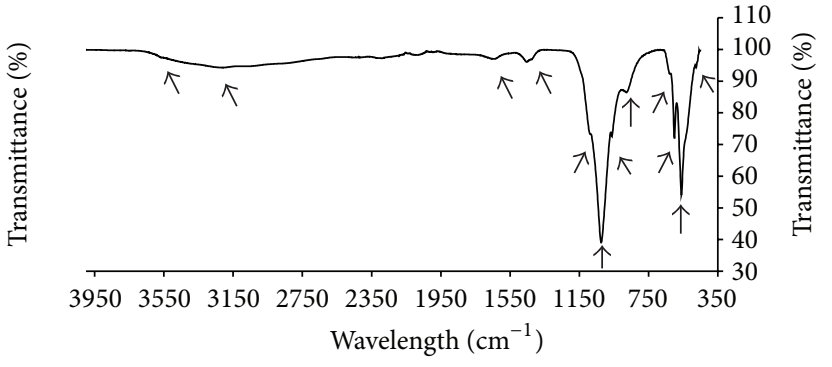

(b)

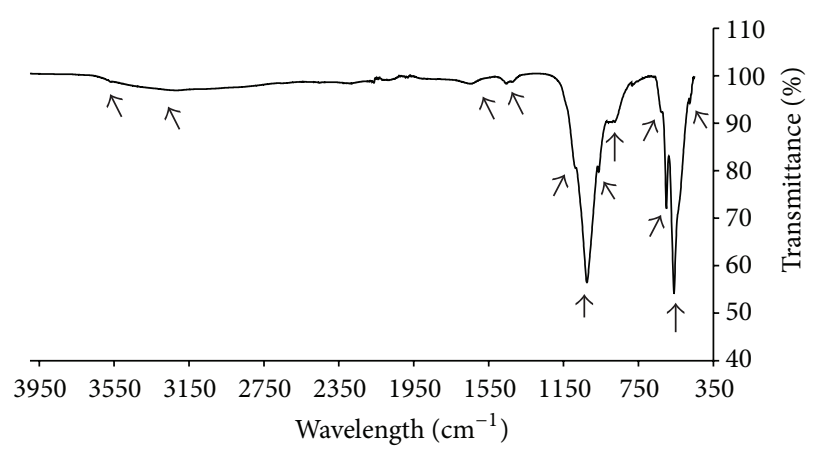

(c)

Figure 3: FTIR spectra of (a) dHA-A900, (b) cHA-900, and (c) dHA-700.

increasing the irradiation time, the agglomeration of particles was less agglomerated but particles from all samples were closely packed. As the time increased, it also can be seen that the particles shape was more uniformly distributed even though their shapes were a bit irregular round shape. As the irradiation time increases, the particle size tended to be larger, that is, $72.48 \mathrm{~nm}, 75.21 \mathrm{~nm}$, and $76.17 \mathrm{~nm}$ for dHA-A900, dHA-B900, and dHA-C900, respectively. It was reported that prolonged microwave irradiation time slowly increased the substance density and decreased the specific surface area. This in turn increased the particles size [29]. Smolen et al. [29] conducted a synthesis of HA with programmed resorption rate using microwave irradiation as a heating mechanism. All the synthesis conditions such as time, temperature, pressure, and microwave power were computer-controlled. They successfully synthesized nonstoichiometric HA in a very short time of $1.5 \mathrm{~min}$. This almost spherical-like HA dimension was $5.6 \mathrm{~nm}$. As the time increased, the particles size was increased and the particles tended to be less agglomerated with mix structure of spherical and needle-like particles. However, longer irradiation time resulted in increment of $\mathrm{Ca} / \mathrm{P}$ molar ratio values and stoichiometric $\mathrm{HA}$ was obtained at $10 \mathrm{~min}$ of irradiation time. There was no change in phase composition and lattice parameters as the time increased. In this study, microwave power showed a significant change in HA morphology. At power of $700 \mathrm{~W}$, the HA particles obtained were almost needle-like shaped with dimension of $38.91 \mathrm{~nm}$ in length and $16.43 \mathrm{~nm}$ in diameter. Although it was agglomerated, the particles were uniformly distributed. This can be seen in Figure 2(a). By utilizing the eggshells biowaste, Siddharthan et al. [30] reported a fabrication of flower-like HA nanostructure by using microwave heating at $600 \mathrm{~W}$ for $10 \mathrm{~min}$. This was done with the aid of ethylenediaminetetraacetic acid (EDTA) which enhanced the crystalline growth. The flower-like nano-HA consisted of leaf-like flakes with dimension of 100-200 nm width and 0.5$1 \mu \mathrm{m}$ length. However, magnesium from the eggshells was found along with HA produced.

The FTIR spectrum of the as-synthesized dHA-A900, cHA-900, and dHA-700 is shown in Figure 3. The FTIR spectrum characteristics of dHA-A900, cHA-900, and dHA700 are shown in Table 2. All the characteristic frequencies of $\mathrm{PO}_{4}{ }^{3-}$ modes [31-34] appeared at the frequencies of (I) $\mathrm{cHA}$ $900 ; 472 \mathrm{~cm}^{-1}, 574 \mathrm{~cm}^{-1}, 601 \mathrm{~cm}^{-1}, 962 \mathrm{~cm}^{-1}, 1023 \mathrm{~cm}^{-1}$, and $1090 \mathrm{~cm}^{-1}$, (II) dHA-A900; $561 \mathrm{~cm}^{-1}, 601 \mathrm{~cm}^{-1}, 962 \mathrm{~cm}^{-1}$, $1024 \mathrm{~cm}^{-1}$, and $1090 \mathrm{~cm}^{-1}$. The stretching vibration of $\mathrm{PO}_{4}{ }^{3-}$ of $\mathrm{V}_{3}$ appeared at $1023 \mathrm{~cm}^{-1}$ and $1090 \mathrm{~cm}^{-1}$; at $1023 \mathrm{~cm}^{-1}$ and $1090 \mathrm{~cm}^{-1}$ for cHA-900 and dHA-A900, respectively.

However, the band at $962 \mathrm{~cm}^{-1}$ (cHA-900 and dHAA900) was assigned to $\mathrm{V}_{1}$ peaks. The double sharp peaks at $560 \mathrm{~cm}^{-1}$ (cHA-900), $561 \mathrm{~cm}^{-1}$ (dHA-A900), and $601 \mathrm{~cm}^{-1}$ (cHA-900 and dHA-A900) were related to $\mathrm{V}_{4}$ of bending modes of $\mathrm{P}-\mathrm{O}$ bonds in phosphate group [33]. While $475 \mathrm{~cm}^{-1}$ (cHA-900 and dHA-A900) was assigned to $\mathrm{V}_{4}$ of $\mathrm{PO}_{4}{ }^{3-}$ modes. These FTIR characteristics of phosphate group confirmed the formation of HA phase. The weak band of liberational mode of structural $\mathrm{OH}$ can be seen at $631 \mathrm{~cm}^{-1}$ and $629 \mathrm{~cm}^{-1}$ for cHA-900 and dHA-A900, respectively. The stretching vibration band of $\mathrm{OH}\left(3542 \mathrm{~cm}^{-1}\right)$ was invisible due to adsorbed water [25] and the presence of small amount of carbonate at frequencies of $\sim 875 \mathrm{~cm}^{-1}$ and $\sim 1450 \mathrm{~cm}^{-1}$ 
TABLE 2: FTIR spectra of cHA-900, dHA-900, and dHA-700.

\begin{tabular}{lccc}
\hline $\begin{array}{l}\text { Corresponding } \\
\text { assignments }\end{array}$ & \multicolumn{3}{c}{ Observed vibrational frequencies $\left(\mathrm{cm}^{-1}\right)$} \\
cHA-900 & dHA-900 & dHA-700 \\
\hline $\mathrm{PO}_{4}{ }^{3-}$ bend $\mathrm{V}_{2}$ & 475 & 475 & 475 \\
$\mathrm{PO}_{4}{ }^{3-}$ bend $\mathrm{V}_{4}$ & 560 & 561 & 560 \\
$\mathrm{PO}_{4}{ }^{3-}$ bend $\mathrm{V}_{4}$ & 601 & 601 & 601 \\
$\mathrm{Structural} \mathrm{OH}^{-}$ & 631 & 629 & 631 \\
$\mathrm{CO}_{3}{ }^{2-}$ & 877 & 879 & 877 \\
$\mathrm{PO}_{4}{ }^{3-}$ stretch $\mathrm{V}_{1}$ & 962 & 962 & 962 \\
$\mathrm{PO}_{4}{ }^{3-}$ bend $\mathrm{V}_{3}$ & 1023 & 1024 & 1023 \\
$\mathrm{PO}_{4}{ }^{3-}$ bend $\mathrm{V}_{3}$ & 1090 & 1090 & 1088 \\
$\mathrm{CO}_{3}{ }^{2-} \mathrm{V}_{3}$ & 1453 & 1454 & 1417 \\
$\mathrm{H}_{2} \mathrm{O}$ adsorbed $\mathrm{V}_{2}$ & 1645 & 1647 & 1648 \\
$\mathrm{H}_{2} \mathrm{O}$ adsorbed & 3214 & 3220 & 3227 \\
Structural OH & 3542 & 3567 & 3570 \\
\hline
\end{tabular}

which was absorbed from atmosphere during the synthesis process [34]. It is common for biological apatite to allow other nonapatite ions substitution such as carbonate, fluoride, and chloride substitutions which substitutes either $\mathrm{OH}^{-}$or $\mathrm{PO}_{4}{ }^{3-}$ groups $[9,19]$. The broad band at $3214 \mathrm{~cm}^{-1}$ (cHA900 ) and $3220 \mathrm{~cm}^{-1}$ (dHA-A900) was assigned to $\mathrm{V}_{3}$ bending mode while peaks at $1645 \mathrm{~cm}^{-1}$ (cHA-900) and $1647 \mathrm{~cm}^{-1}$ (dHA-A900) corresponded to $\mathrm{V}_{2}$ bending mode of adsorbed water molecules. The FTIR spectrum characteristics of HA for sample dHA-700 can be seen in Table 2. As the time increased, all the FTIR spectra occurred and there was no indication of substitution of other functional groups.

\section{Conclusion}

By using both chicken and duck eggshells, irregular circular nanosized HA powders were successfully synthesized with only $15 \mathrm{~min}$ of irradiation time with no secondary phases or impurities found. An increase of irradiation time has no effect on the phase composition but there was a slight difference on the particles morphology. By varying the microwave power, various shapes of HA particles can be achieved. The usage of various biowaste materials and microwave heating to fabricate HA has been proven to be low cost, efficient, and fastest technique as the whole process only took about 5 hours from preparation of precursors, mixing of chemical solution, and microwave irradiation to formation of precipitate.

\section{Conflict of Interests}

The authors declare that there is no conflict of interests regarding the publication of this paper.

\section{Acknowledgment}

The authors acknowledge the financial support of Postgraduate Research Grant (PPP), University of Malaya, Project PV012-2012A.

\section{References}

[1] E. Nejati, H. Mirzadeh, and M. Zandi, "Synthesis and characterization of nano-hydroxyapatite rods/poly(l-lactide acid) composite scaffolds for bone tissue engineering," Composites Part A: Applied Science and Manufacturing, vol. 39, no. 10, pp. 1589-1596, 2008.

[2] H. Zhou and J. Lee, "Nanoscale hydroxyapatite particles for bone tissue engineering," Acta Biomaterialia, vol. 7, no. 7, pp. 2769-2781, 2011.

[3] Y. Ohbayashi, M. Miyake, and S. Nagahata, "A long-term study of implanted artificial hydroxyapatite particles surrounding the carotid artery in adult dogs," Biomaterials, vol. 21, no. 5, pp. 501509, 2000.

[4] P. Wang, C. Li, H. Gong, X. Jiang, H. Wang, and K. Li, "Effects of synthesis conditions on the morphology of hydroxyapatite nanoparticles produced by wet chemical process," Powder Technology, vol. 203, no. 2, pp. 315-321, 2010.

[5] S. Pramanik, A. K. Agarwal, and K. N. Rai, "Development of high strength hydroxyapatite for hard tissue replacement," Trends in Biomaterials and Artificial Organs, vol. 19, no. 1, pp. 46-51, 2005.

[6] P. Dasgupta, A. Singh, S. Adak, and K. M. Purohit, "Synthesis and characterization of hydroxyapatite produced from eggshell," in Proceedings of the International Symposium of Research Students on Materials Science and Engineering, pp. 2022, 2004

[7] A. Singh and K. M. Purohit, "Chemical synthesis, characterization and bioactivity evaluation of hydroxyapatite prepared from garden snail (helix aspersa)," Journal of Biotechnology \& Biomaterials, vol. 1, p. 104, 2011.

[8] P. Hui, S. L. Meena, G. Singh, R. D. Agarawal, and S. Prakash, "Synthesis of hydroxyapatite bio-ceramic powder by hydrothermal method," Journal of Minerals and Materials Characterization and Engineering, vol. 9, no. 8, pp. 683-692, 2010.

[9] S. J. Kalita and S. Verma, "Nanocrystalline hydroxyapatite bioceramic using microwave radiation: synthesis and characterization," Materials Science and Engineering C, vol. 30, no. 2, pp. 295-303, 2010.

[10] S. Jadalannagari, S. More, M. Kowshik, and S. R. Ramanan, "Low temperature synthesis of hydroxyapatite nano-rods by a modified sol-gel technique," Materials Science and Engineering C, vol. 31, no. 7, pp. 1534-1538, 2011.

[11] J. S. Earl, D. J. Wood, and S. J. Milne, "Hydrothermal synthesis of hydroxyapatite," Journal of Physics: Conference Series, vol. 26, no. 1, pp. 268-271, 2006.

[12] K. P. Sanosh, M.-C. Chu, A. Balakrishnan, Y.-J. Lee, T. N. Kim, and S.-J. Cho, "Synthesis of nano hydroxyapatite powder that simulate teeth particle morphology and composition," Current Applied Physics, vol. 9, no. 6, pp. 1459-1462, 2009.

[13] Y.-M. Sung, J.-C. Lee, and J.-W. Yang, "Crystallization and sintering characteristics of chemically precipitated hydroxyapatite nanopowder," Journal of Crystal Growth, vol. 262, no. 1-4, pp. 467-472, 2004.

[14] S. K. Padmanabhan, A. Balakrishnan, M.-C. Chu, Y. J. Lee, T. N. Kim, and S.-J. Cho, "Sol-gel synthesis and characterization of hydroxyapatite nanorods," Particuology, vol. 7, no. 6, pp. 466470, 2009.

[15] K. C. B. Yeong, J. Wang, and S. C. Ng, "Mechanochemical synthesis of nanocrystalline hydroxyapatite from $\mathrm{CaO}$ and $\mathrm{CaHPO}_{4}$," Biomaterials, vol. 22, no. 20, pp. 2705-2712, 2001. 
[16] C. Kothapalli, M. Wei, A. Vasiliev, and M. T. Shaw, "Influence of temperature and concentration on the sintering behavior and mechanical properties of hydroxyapatite," Acta Materialia, vol. 52, no. 19, pp. 5655-5663, 2004.

[17] J. L. Acevedo-Dávila, J. López-Cuevas, G. Vargas-Gutiérrez, J. C. Rendón-Angeles, and J. Méndez-Nonell, "Chemical synthesis of bone-like carbonate hydroxyapatite from hen eggshells and its characterization," Boletin de la Sociedad Espanola de Ceramica $y$ Vidrio, vol. 46, no. 5, pp. 225-231, 2007.

[18] X. Zhang and K. S. Vecchio, "Hydrothermal synthesis of hydroxyapatite rods," Journal of Crystal Growth, vol. 308, no. 1, pp. 133-140, 2007.

[19] S. Meejoo, W. Maneeprakorn, and P. Winotai, "Phase and thermal stability of nanocrystalline hydroxyapatite prepared via microwave heating," Thermochimica Acta, vol. 447, no. 1, pp. 115-120, 2006.

[20] J. Liu, K. Li, H. Wang, M. Zhu, and H. Yan, "Rapid formation of hydroxyapatite nanostructures by microwave irradiation," Chemical Physics Letters, vol. 396, no. 4-6, pp. 429-432, 2004.

[21] H. Arami, M. Mohajerani, M. Mazloumi, R. Khalifehzadeh, A. Lak, and S. K. Sadrnezhaad, "Rapid formation of hydroxyapatite nanostrips via microwave irradiation," Journal of Alloys and Compounds, vol. 469, no. 1-2, pp. 391-394, 2009.

[22] S. Nayar and A. Guha, "Waste utilization for the controlled synthesis of nanosized hydroxyapatite," Materials Science and Engineering C, vol. 29, no. 4, pp. 1326-1329, 2009.

[23] B. Matthew, J. M. Steven, and P. B. Andrew, "Comparison of hydrothermal and sol-gel synthesis of nano-particulate hydroxyapatite by characterisation at the bulk and particle level," Open Journal of Inorganic Non-metallic Materials, vol. 2, no. 1, pp. 1$10,2012$.

[24] R. Palanivelu, A. Mary Saral, and A. Ruban Kumar, "Nanocrystalline hydroxyapatite prepared under various $\mathrm{pH}$ conditions," Spectrochimica Acta Part A: Molecular and Biomolecular Spectroscopy, vol. 131, pp. 37-41, 2014.

[25] K. Prabakaran, A. Balamurugan, and S. Rajeswari, "Development of calcium phosphate based apatite from hen's eggshell," Bulletin of Materials Science, vol. 28, no. 2, pp. 115-119, 2005.

[26] A. J. Nathanael, S. I. Hong, D. Mangalaraj, and P. C. Chen, "Large scale synthesis of hydroxyapatite nanospheres by high gravity method," Chemical Engineering Journal, vol. 173, no. 3, pp. 846-854, 2011.

[27] H. S. Liu, T. S. Chin, L. S. Lai et al., "Hydroxyapatite synthesized by a simplified hydrothermal method," Ceramics International, vol. 23, no. 1, pp. 19-25, 1997.

[28] N. Monmaturapoj, "Nano-size hydroxyapatite powders preparation by wet-chemical precipitation route," Journal of Metals, Materials and Minerals, vol. 18, no. 1, pp. 15-20, 2008.

[29] D. Smoleń, T. Chudoba, S. Gierlotka et al., "Hydroxyapatite nanopowder synthesis with a programmed resorption rate," Journal of Nanomaterials, vol. 2012, Article ID 841971, 9 pages, 2012.

[30] A. Siddharthan, T. S. Sampath Kumar, and S. K. Seshadri, "Synthesis and characterization of nanocrystalline apatites from eggshells at different Ca/P ratios," Biomedical Materials, vol. 4, no. 4, Article ID 045010, 9 pages, 2009.

[31] S. Ahmed and M. Ahsan, "Synthesis of Ca-hydroxyapatite bioceramic from egg shell and its characterization," Bangladesh Journal of Scientific and Industrial Research, vol. 43, no. 4, pp. 501-512, 2008.
[32] A. Singh, "Hydroxyapatite, a biomaterial: its chemical synthesis, characterization and study of biocompatibility prepared from shell of garden snail, Helix aspersa," Bulletin of Materials Science, vol. 35, no. 6, pp. 1031-1038, 2012.

[33] G. S. Kumar, A. Thamizhavel, and E. K. Girija, "Microwave conversion of eggshells into flower-like hydroxyapatite nanostructure for biomedical applications," Materials Letters, vol. 76, pp. 198-200, 2012.

[34] Z. Zou, K. Lin, L. Chen, and J. Chang, "Ultrafast synthesis and characterization of carbonated hydroxyapatite nanopowders via sonochemistry-assisted microwave process," Ultrasonics Sonochemistry, vol. 19, no. 6, pp. 1174-1179, 2012. 

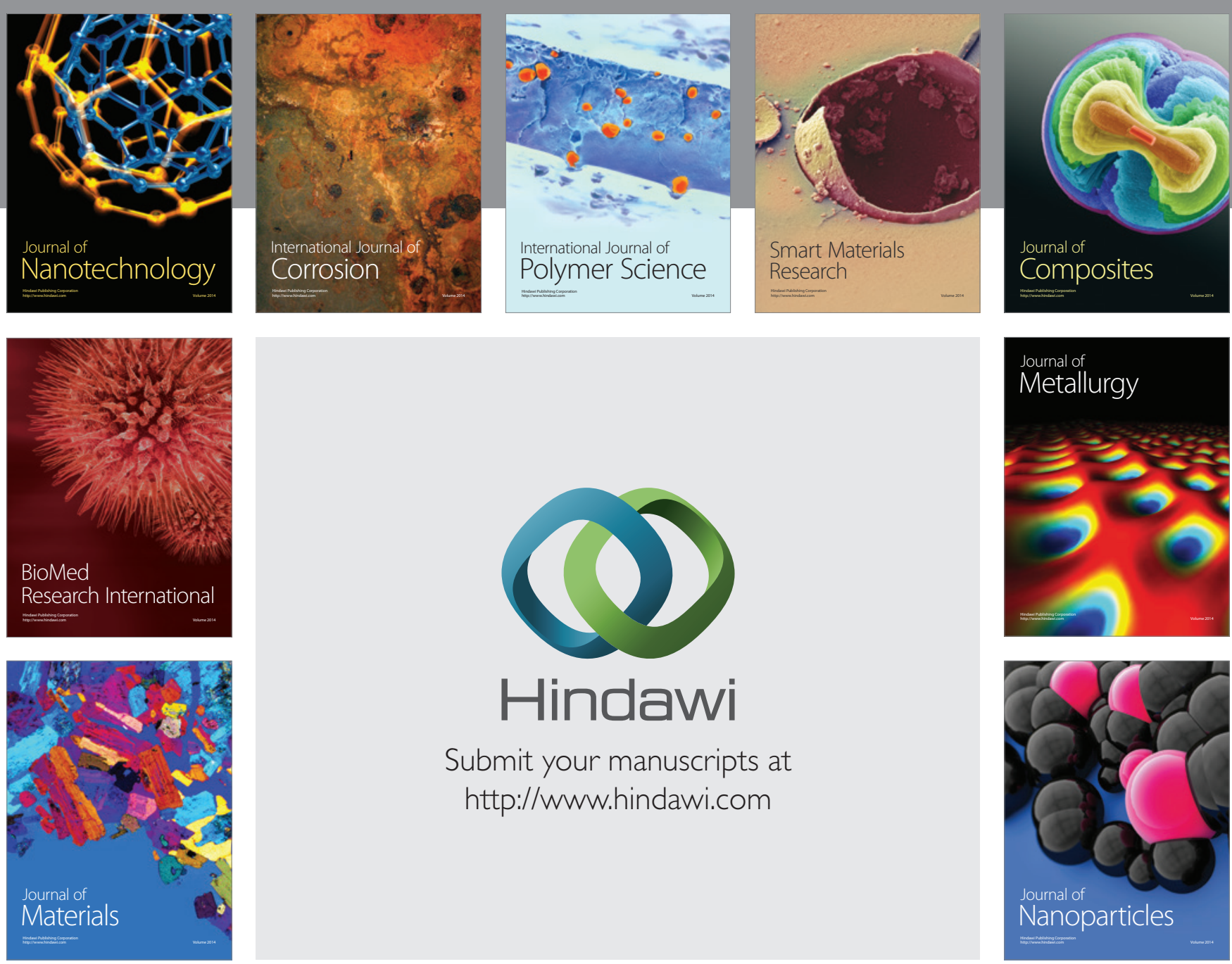

Submit your manuscripts at http://www.hindawi.com
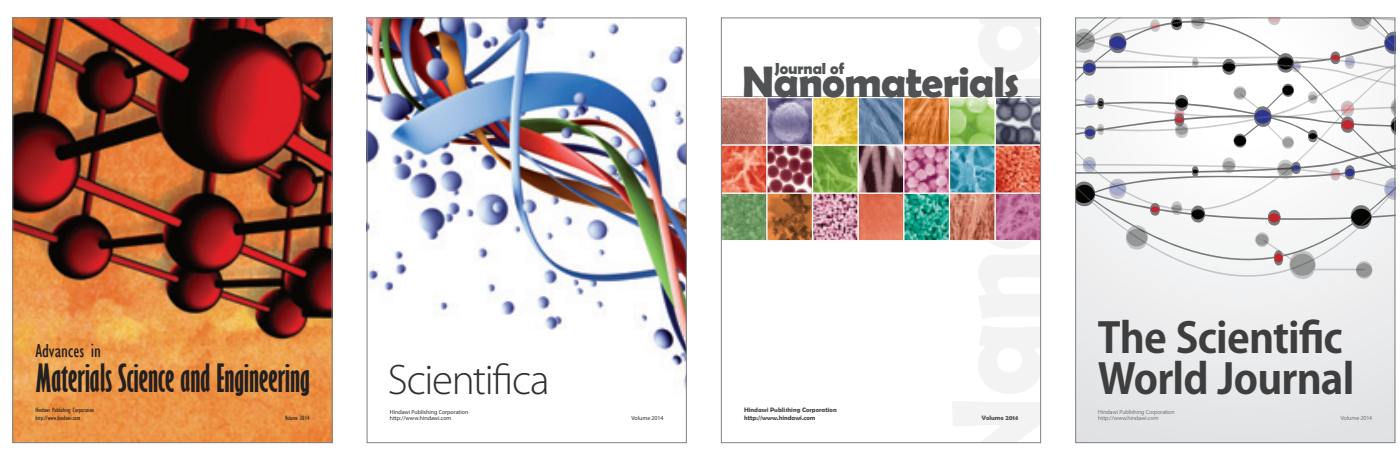

\section{The Scientific World Journal}
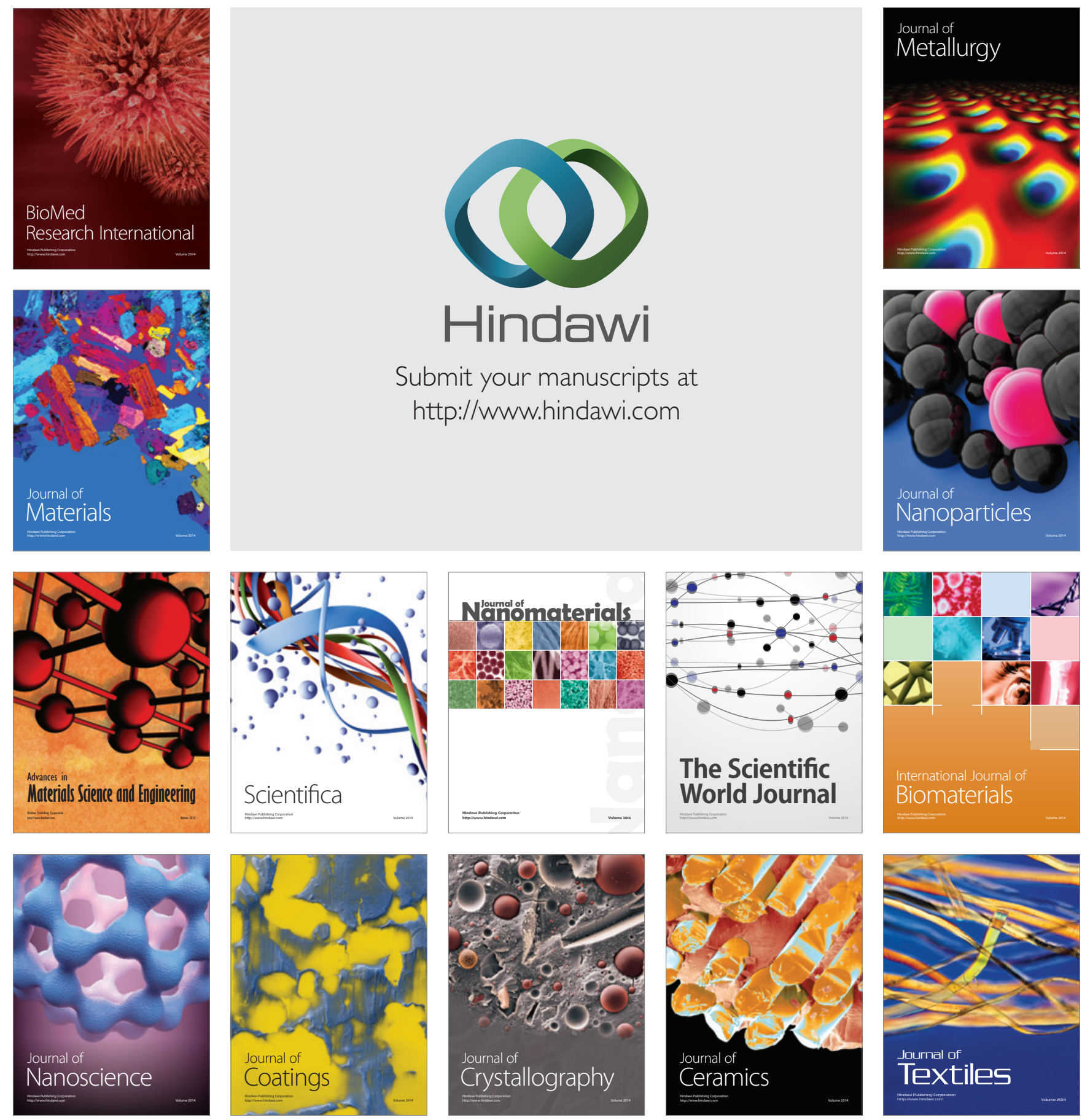